\title{
A new tool for genotoxic risk assessment: Reevaluation of the cytokinesis- block micronucleus assay using semi-automated scoring following telomere and centromere staining
}

Narjes Zaguia ${ }^{1-2}$, Eric Laplagne ${ }^{3}$, Bruno Colicchio ${ }^{5}$, Cariou Olivier ${ }^{4}$, Mustafa Al Jawhari ${ }^{1}$, Leonhard Heidingsfelder ${ }^{6}$, William M. Hempel ${ }^{1}$, Besma Bel Hadj Jrad ${ }^{2}$, Eric Jeandidier ${ }^{7}$, Alain Dieterlen ${ }^{5}$, Patrice Carde ${ }^{8}$, Philippe Voisin ${ }^{1}$ and Radhia M'kacher 1

${ }^{1}$ Cell Environment DNA damage R\&D, 75020 Paris, France

${ }^{2}$ Institut Supérieur de Biotechnologie de Monastir, Université de Monastir Monastir, Tunisie

${ }^{3}$ Pole Concept, Paris, France

${ }^{4}$ Genevoulution Laboratory, Porcheville, France,

${ }^{5}$ IRIMAS, Institut de Recherche en Informatique, Mathématiques, Automatique et Signal, Université de Haute-Alsace, Mulhouse 68093 France

${ }^{6}$ MetaSystems GmbH, Robert-Bosch-Str. 6 D-68804 Altlussheim, Germany

${ }^{7}$ Department of Genetics, Groupe Hospitalier de la Région de Mulhouse Sud-Alsace, Mulhouse 68093, France

${ }^{8}$ Departement of Hematology, Gustave Roussy Cancer Campus, 94805 Villejuif, France

Corresponded author: Dr Radhia M'kacher, Cell Environment DNA damage R\&D, 75020 Paris France 


\begin{abstract}
:
Background: The cytokinesis-block micronucleus (CBMN) assay is an internationally recognized method for measuring DNA damage after exposure to genotoxic agents, as well as a biomarker for DNA repair and chromosomal instability. The high baseline level of micronuclei $(\mathrm{MN})$ in the healthy population has limited the sensitivity and application of the CBMN assay for the follow-up of exposed populations. We reevaluated the sensitivity of the CBNM assay using semi-automated MN scoring following telomere and centromere (TC) staining after in vitro exposure to genotoxic agents (mitomycin or radiation) or aneugenic agents (vinblastine).
\end{abstract}

Materials and methods: Blood samples from 12 healthy donors were exposed to ${ }^{137} \mathrm{Cs}$ at seven doses from 0.1 to $4 \mathrm{~Gy}$ and cultured for $72 \mathrm{~h}$. Cytochalasin B was added at $46 \mathrm{~h}$ of culture. The exposure of chemical agents (mitomycin or vinblastine) was performed after $48 \mathrm{~h}$ of culture for $3 \mathrm{~h}$. Cytochalasin B was added after treatment and slides were prepared $24 \mathrm{~h}$ after. MN was semi-automatically scored following TC staining. Nucleoplasmic bridges (NPBs) and nuclear buds (NBUDs) were assessed in a human cell line after TC staining.

Results: The introduction TC staining to the scoring of MN not only renders $\mathrm{MN}$ scoring more efficient and robust, but also permits discrimination between exposure to clastogenic (MN with only telomere signals) and aneugenic agents (MN with both TC signals). The resulting improvement of $\mathrm{MN}$ detection led to an increase in the sensitivity of the CBMN assay following low-dose radiation exposure (0.3 versus 0.1 Gy). Hyperradiosensitivity phenomenon was observed after low dose exposure. A dose-response curve was obtained for up to $4 \mathrm{~Gy}$. In addition, TC staining permits assessment of the nature of NPBs and NBUDs as biomarkers for genotoxicity and chromosomal instability.

Conclusion: These approaches can be potentially used to follow-up populations exposed to genotoxic agents and assess cancer risk.

Key words: MN, telomere, centromere, clastogen, aneugen, radiation 


\section{Introduction}

The cytokinesis-block micronucleus $(\mathrm{CBMN})$ assay is an internationally recognized method for determining the genotoxic potential of substances and agents, recommended by the OECD for genotoxicity testing [1] and the AIEA for biological dosimetry [2]. Micronuclei (MN) contain either acentric or whole chromosomes and are formed in dividing cells.

The scoring of $\mathrm{MN}$ is well validated for not only measuring DNA damage in vivo and in vitro [3] after exposure to genotoxic agents, but is also an established biomarker of DNA repair efficiency and chromosomal instability [4]. A high frequency of MN has been associated with an increased risk of cancer in a large cohort of patients [5-9]. In addition, the scoring of $\mathrm{MN}$ in circulating lymphocytes has been used for the follow-up of populations exposed to genotoxic agents [10-14]. The major drawback of this technique is the high baseline of MN in heathy populations, which was limited the sensitivity (detection limit of 0.2-0.3 Gy) and application of the CBMN assay for the follow-up of exposed populations. Confounding factors (age, sex, diet, and lifestyle) can significantly influence the frequency of MN in peripheral blood lymphocytes $[5,15]$.

The CBMN assay, combined with fluorescence in situ hybridization (FISH) using pancentromeric probes, has been shown to discriminate between clastogenic (MN without centromere staining) and aneugenic effects (MN with centromere staining) [16-19] and increase the sensitivity of this technique [14]. The FISH-based MN-centromere assay requires two days to perform, which is a major limitation of this technique for biological dosimetry (added to three days of culture) and genetic toxicology testing, in addition to the high cost of the DNA probes. FISH-based MN has thus not been widely adopted.

The introduction of peptide nucleic acid (PNA) probes to the scoring of radiation-induced DNA damage opens new horizons for this application [20]. We have recently demonstrated the high efficiency of telomere and centromere (TC) staining for the scoring of dicentric and ring chromosomes in metaphases [21] and non-stimulated lymphocyte prematurely condensed chromosomes [22]. We have also successfully reevaluated the transmission of chromosomal aberrations using this approach [23]. PNA probes have the advantage of short hybridization times, high specificity and signal intensity, and low cost. In addition, there are existing tools for the automation of MN scoring following uniform staining (Giemsa or DAPI staining) [24, 25]. 
Here, we show that the association of TC staining with the automatic scoring of MN allows: 1) easier detection of $\mathrm{MN}$ than by uniform staining; 2) better detection of different types of $\mathrm{MN}$, leading to the distinction between exposure to clastogenic ( $\mathrm{MN}$ with only telomere signals or MN without any signal) and aneugenic agents (MN with telomere and centromere signals); and 3) improvement of the sensitivity of the CBMN assay and the dose-response curve using semi-automated MN scoring following TC staining after exposure to chemical agents or ionizing radiation. We also demonstrate that TC staining enhances the detection of other nuclear abnormalities using the CBMN assay, such as nucleoplasmic bridges (NPBs) and nuclear bud (NBUDs), improving their use as biomarkers of genotoxicity and chromosomal instability.

\section{Materials and Methods}

\section{1-Irradiation procedure and MN preparation}

Peripheral blood samples were obtained from 12 healthy donors (four women and eight men, mean age 37.1 years (20-58 years)) and exposed to gamma irradiation using an IBL637 ${ }^{137} \mathrm{Cs}$ irradiator at seven different doses $(0,0.1,0.2,0.5,1,2$, and $4 \mathrm{~Gy})$ at a dose rate of $0.61 \mathrm{~Gy} / \mathrm{min}$.

Blood lymphocytes were cultured for $72 \mathrm{~h}$ in RPMI 1640 (without L-glutamine with HEPES Invitrogen, France) supplemented with $1 \%$ penicillin/streptomycin $(10,000 \mathrm{UI} / \mathrm{mL} / 10,000$ $\mu \mathrm{g} / \mathrm{mL}$, Invitrogen, France), 1\% 200 mM L-glutamine (Invitrogen, France), 10\% inactivated foetal serum (Invitrogen, France), and 2\% Phytohemagglutinin (PHA Remel HA15). Cytochalasin B (from Drechslera dematioidea, Sigma) $(6 \mu \mathrm{g} / \mathrm{mL})$ was added $24 \mathrm{~h}$ before arrest according to standard procedures $[1,2]$. Slides were spread and stored at $-20^{\circ} \mathrm{C}$ until use [26].

\section{2- Exposure to chemical agents}

Blood lymphocytes were similarly cultured using RPMI 1640 as mentioned previously. After $48 \mathrm{~h}$ of culture, cells were exposed for $3 \mathrm{~h}$ to various concentrations of aneugenic (vinblastine) or clastogenic (mitomycin C) substances. The highest concentrations of each induced only weak cytotoxicity. Cytochalasin B was added immediately after washing the cells. After $24 \mathrm{~h}$, cultures were harvested according to standard procedures [1, 2]. 


\section{3-Cell lines used to detect nucleoplasmic bridges and nuclear buds}

HDLM2 Hodgkin lymphoma [27] (Diehl V 1985) and DAUDI Burkitt lymphoma [28] cell lines were used to assess the detection of NPBs and NBUDs after TC staining. Cell lines were cultured in RPMI and harvested as mentioned previously [29].

\section{4-Telomere-Centromere staining}

The scoring of MN was performed using TC staining as described previously [21]. Briefly, slides were washed with $1 \mathrm{X}$ PBS for $5 \mathrm{~min}$ at room temperature. Fixation was performed with $4 \%$ formaldehyde for $2 \mathrm{~min}$ at room temperature and the slides washed three times with PBS for $5 \mathrm{~min}$. After $7 \mathrm{~min}$ of pepsin treatment $(0.5 \mathrm{mg} / \mathrm{ml})$ at $37^{\circ} \mathrm{C}$, the slides were washed in PBS and refixed in $4 \%$ formaldehyde for $2 \mathrm{~min}$. After three PBS washes during $5 \mathrm{~min}$, slides were sequentially dehydrated with 50\%, 70\%, and 100\% ethanol and air-dried. The probe solution consisted of $50 \mu \mathrm{L}$ PNA probe $(0.3 \mu \mathrm{g} / \mathrm{mL}$ telomere and centromere). The slides with the probe solution were denatured on a hot plate at $80^{\circ} \mathrm{C}$ for $3 \mathrm{~min}$ and incubated in the dark for 1 $\mathrm{h}$ at room temperature. After hybridization, the slides were washed three times with $70 \%$ formamide/10mM Tris $\mathrm{pH} 7.2$ during $15 \mathrm{~min}$ and then $3 \times 5 \mathrm{~min}$ in $50 \mathrm{mM}$ Tris $\mathrm{pH}$ 7.2/150mM NaCl pH 7.5/0.05\% Tween_20. After washing with PBS, the slides were counterstained with DAPI and mounted with PPD.

\section{5-MN scoring}

Automatic scoring of MN was performed using MNScore software (version 3.8.101

MetaSystems, Althaussen, Germany) with a Metafer 4 image analyser (MetaSystems, Althaussen, Germany) comprised of a Zeiss Axioplan 2 imager [30, 31] to detect MN. An operator validated and excluded the false $\mathrm{MN}$ in bi-nucleate cells. For each sample, 1000 binucleated cells were scored.

To detect the presence of centromere and/or telomere signals, bi-nucleate cells with MN were acquired using automated acquisition module Autocap software (MetaSystems, version 3.9.1) and a ZEISS Plan-Apochromat 63x/1.40 oil and CoolCube 1 Digital High Resolution CCD Camera. Images were analyzed using Isis software (Metasystems, version 3.9.1).

We scored $\mathrm{MN}$ with $\mathrm{TC}$ staining $(\mathrm{MN}-\mathrm{T}+\mathrm{C})$, which predominantly contain lagging chromosomes. We also scored MN with only telomere staining (MN-T), resulting mainly from acentric chromosomes, and $\mathrm{MN}$ with no staining, resulting from interstitial deletions. 


\section{6-Statistical analysis}

All plots were created using $\mathrm{R}$ and the gplots 2.1.0 package. The 95\% confidence interval limits were calculated using the exact Poisson method. The upper and lower limits were calculated using the chi 2 distribution function, as an R command named qchisq(p,df) where $p$ is the probability and df the degree of freedom.

Linear regression was performed to fit the data (slope and intercept) using the least squares method. The grey areas outline the $95 \%$ confidence intervals implemented using the geom_smooth() R graphic command. The ratio rate test was performed using Test library in $\mathrm{R}$ software.

\section{Results}

\section{1-Improvement of the detection of MN by TC staining}

The detection of MN using the conventional CBMN assay is based on MN morphology following uniform staining (Giemsa or DAPI). However, the intensity of DAPI staining of the $\mathrm{MN}$ is very weak relative to that of the nucleus (Figure1A). Telomere and centromere staining allowed visualization of centromere and telomere sequences contributing to an improvement in the detection of MN (Figure 1B). In addition, TC staining also allowed the easy identification of the cytoplasmic skeleton due to a slight fluorescent background, representing another advantage of this approach (Figure 1B-C) that requires no further steps. The use of PNA probes, characterized by their high signal intensity and much lower cost than DNA probes, does not substantially increase the cost over that of uniform staining, nor the time of hybridization ( $1 \mathrm{~h}$ vs $16 \mathrm{~h}$ of DNA probe hybridization).

\section{2-Occurrence of spontaneous MN following TC staining}

Before any exposure, we scored a total of $125 \mathrm{MN}$ in 9,396 bi-nucleate cells from 12 healthy donors in this study, including $90 \mathrm{MN}-\mathrm{T}+\mathrm{C}$ (72\%) with both TC staining, $33 \mathrm{MN}-\mathrm{T}(26.4 \%)$, and $2 \mathrm{MN}(1.6 \%)$ without telomere or centromere staining, reflecting interstitial deletions. The total frequency of MN was significantly higher in women (23.51 per 1000 bi-nucleate cells) than in men $(10.21$ per 1000 bi-nucleate cells $)\left(\mathrm{p}<10^{-6}\right)$, due essentially to the higher frequency of $\mathrm{MN}-\mathrm{T}+\mathrm{C}$ in women (19.36 MN per 1000 bi-nucleate cells) than in men (11.69 MN per 1000 bi-nucleate cells) $\left(\mathrm{P}<10^{-7}\right)$. Age (more than 40 years) was associated with an increased frequency of spontaneous $\mathrm{MN}$ in our cohort (21.82 MN per 1000 bi-nuclei in healthy donors aged 40 years or more vs $10.81 \mathrm{MN}$ per 1000 bi-nuclei in donors less than 40 years old $)\left(\mathrm{p}<10^{-3}\right)$, associated not only with the an increase in the frequency of MN-T+C 
(16.13 vs 7.66 per 1000 bi-nuclei) $\left(\mathrm{P}<10^{3}\right)$, but also an increase of MN-T(6.64 vs 2.87) $(\mathrm{p} \leq$ $0.02)$.

\section{3-Discrimination of clastogenic and aneugenic effects after exposure}

The introduction of TC staining to the CBMN assay permitted the scoring of different MN figures according to the presence of telomere and centromere sequences. We detected $\mathrm{MN}-\mathrm{T}$ (Figure1D), containing acentric fragments, as well as MN without any signal, containing interstitial deletions (Figure 1E). We also detected MN-T+C (Figure 1E), reflecting mitotic errors that produced lagging chromosomes. This information provided by TC staining allowed us to determine the nature of the including agent: clastogenic (MN-T, as well as MN without any signal) or aneugenic $(\mathrm{MN}-\mathrm{T}+\mathrm{C})$.

After three hours of treatment with mitomycin C, a clastogenic substance, we found a significantly higher frequency of MN-T than MN-T+C (Figure 2A). In contrast, three hours of treatment with vinblastine, an aneugenic substance, resulted in a significantly high frequency of MN-T+C than MN-T (Figure 2B). The frequency of MN without any signal represented a very small part of the DNA damage response and can be added to the frequency of MN with telomere staining.

\section{4-Increased sensitivity of the semi-automated CBMN assay following TC staining}

We assessed the sensitivity of the semi-automated CBMN technique following TC staining to $\gamma$-ray irradiation using ${ }^{137} \mathrm{Cs}$ (dose rate $0.61 \mathrm{~Gy} / \mathrm{min}$ ). Following TC staining, it was possible to detect a difference between control and the lowest dose tested $(0.1 \mathrm{~Gy})\left(\mathrm{P}<10^{-16}\right)$ after the scoring of the total MN. The frequency of MN-T and MN-T+C were significantly higher after $0.1 \mathrm{~Gy}\left(\mathrm{P}<10^{-10} ; \mathrm{P}<10^{-11}\right.$ respectively).

\section{5-Dose response curve using the CBMN assay followed by TC staining}

Figure 3 (A-B) shows the dose response curve obtained after irradiation by scoring total MN, $\mathrm{MN}-\mathrm{T}$, and $\mathrm{MN}-\mathrm{T}+\mathrm{C}$. The frequency of $\mathrm{MN}$ without any signal was added to the frequency of $\mathrm{MN}-\mathrm{T}$. Low dose exposure resulted in an increase in the frequency of $\mathrm{MN} \mathrm{T}+\mathrm{C}$ (aneugenic effect) for doses up to $0.5 \mathrm{~Gy}$ (figure3B). The relationship between the frequency of $\mathrm{MN} \mathrm{T}+\mathrm{C}$ and MN-T was linear at low doses, but disappeared with increasing dose (Figure 4A), confirming the aneugenic potential of low-dose exposure.

Interestingly, we observed a disproportionate frequency of $\mathrm{MN}-\mathrm{T}$ and $\mathrm{MN}-\mathrm{T}+\mathrm{C}$, given the frequency of MN per unit of dose after low-dose exposure (Figure 4B). Such high radiation 
sensitivity was observed in the lowest tested dose in this study (100 mGy). A local concavity on dose response curve was observed in low dose (figure 3B). Therefore, as linear quadratic model tends to a pure linear one when tend to zero, it becomes impossible to fit properly any form of curvature. These data pointed out weaknesses of linear quadratic model, especially for low dose modeling.

\section{6-CBMN assay following TC staining allows the scoring of nucleoplasmic bridges (NPBs) and nuclear buds (NBUDs)}

The CBMN assay not only permits detection of MN but also the presence of NPBs and NBUDs. NPBs resulting from dicentric chromosomes due to the misrepair of DNA double stranded breaks are characterized by the absence of telomere and centromere signals, associated with the presence of MN with only telomere signals (Figure 5A). We found this type of NPB after exposure to a genotoxic agent, such as ionizing radiation. NBPs with telomere and centromere sequences without an associated $\mathrm{MN}$ can result in dicentric chromosomes due to telomere dysfunction (figure 5B). The use of the HDLM2 Hodgkin lymphoma cell line allowed demonstration of the link between telomere dysfunction, dicentric chromosomes, and the formation of NBPs with centromere sequences. NBUDs were also assessed to study the process of elimination of amplified DNA possibly generated via Breakage/Fusion/Bridge cycles and the process of elimination of excess chromosomes, which may occur in polyploidy cells to facilitate aneuploidy rescue (Figure4C-D). The DAUDI Burkitt cell line showed the presence NBUD with TC staining as well NBUDs with only telomere staining or without any signal.

\section{Discussion}

The CBMN assay applied to peripheral blood lymphocytes is a standard cytogenetic technique for genetic toxicology and biological dosimetry that provides good reliability and reproducibility without requiring a high level of expertise. The existing tools for the automation of $\mathrm{MN}$ scoring permits large-scale use of the CBMN assay not only for regulatory testing in genetic toxicology [1], but also in the field of radiation protection to assess medical $[32,33]$ or professional exposure [14].

Here, we introduce, for the first time, TC staining using PNA probes, permitting the reliable detection of MN with high precision and sensitivity, as well as an improvement in the elucidation of the nature of exposition. 
Increasing the quality of the automated CBMN assay naturally requires better detection of MN. Here, we demonstrated not only an improvement in MN visualization following TC staining, but also the detection of cytoplasm without additional technical steps. TC sequences in $\mathrm{MN}$ allowed determination of the nature of the agent or substance with high precision: clastogen (MN-T or no staining) or aneugen $(\mathrm{MN}-\mathrm{T}+\mathrm{C})$. Thus, we demonstrated an increased frequency of MN-T after mitomycin $\mathrm{C}$ and $\mathrm{MN}-\mathrm{T}+\mathrm{C}$ sequences after vinblastine exposure. This approach should be extended to provide insight into the types of cellular damage induced by new chemical substances used for a wide range of applications, including healthcare [34].

One of major drawback of the CBMN assay is the high frequency of spontaneous $\mathrm{MN}$ in the healthy population, making it difficult to apply this approach to a mass casualty event or the follow-up of a large cohort exposed to low doses of genotoxic agents. The human micronucleus (HUMN) consortium has shown that the frequency of spontaneous $\mathrm{MN}$ is related to age and gender $[15,35]$. Previous studies have demonstrated the presence of TC sequences in most spontaneous MN using pancentromeric and pantelomeric probes [36, 37]. In addition, the frequency of $\mathrm{X}$ chromosomes in the $\mathrm{MN}$ of women is disproportionally high and is age dependent [38-40]. Here, the use of semi-automated MN scoring following TC staining confirmed the age and gender-dependent spontaneous occurrence of MN and showed that they consist essentially of MN-T+C (more than 70\%). The scoring of the telomere signal in these $\mathrm{MN}$ demonstrated that $37 \%$ had only one telomere signal, indicating telomere deletion. Sequential analysis using TC staining followed by the M-FISH technique in a large cohort over a wide range of ages, could improve our knowledge of the nature of spontaneous $\mathrm{MN}$ and the relationship between telomere dysfunction (telomere loss) and the lagging of chromosome.

The use of the semi-automated CBMN assay has led to an increase in the sensitivity of CBMN assay. After uniform staining, it is possible to detect an exposure ranging 0.2-0.3 Gy $[2,5]$. The recent combination of CBMN automation with fluorescence in situ hybridization (FISH), using pan-centromeric DNA probes, has increased the sensitivity of the assay (0.050.1 Gy) [14]. Here, using the semi-automated CBMN assay following TC staining, we successfully detected a high frequency of MN after exposure to the lowest tested dose $0.1 \mathrm{~Gy}$, significantly increasing the sensitivity relative to previous studies $[14,41]$. The ability to detect doses below 0.1 Gy can now be tested in future studies. The increasing sensitivity of the semi-automated CBMN assay following TC staining makes it possible to apply this technique to the field of low-dose radiation research. Low-dose exposure due to natural 
background [42], as well as radio-diagnostic procedures (CT scan), is inevitable and an ongoing health concern [43].

Furthermore, the use of the semi-automated CBMN assay following TC staining allowed determination of the nature of exposure with higher precision. The discrimination of the clastogenic and aneugenic effects of substances is important in the characterization of new chemical agents. Using TC staining, we successfully detected the clastogeneic effect of mytomecine, as well as aneugenic effect of vinblastine. We demonstrate also the clastogenic effect of high-dose of irradiation. In addition, we detected the aneugenic effect of low-dose irradiation. We confirmed the data obtained after in vitro [44, 45] and in vivo [45, 46] exposure to low-dose radiation. We established linear relationships between MN-T and MN$\mathrm{T}+\mathrm{C}$ after low-dose $\gamma$-ray exposure ( 0 up to $0.5 \mathrm{~Gy}$ ). The aneugenic effect of ionizing radiation has been previously suggested but not used in the estimation of risk associated to radiation exposure. Here, we successfully applied TC staining to the CBMN assay to detect the aneugenic activity of low-dose irradiation in addition to clastogenic effects. This data could be used in the triage of accidentally exposed populations to determine the range of the dose received based on the rate of $\mathrm{MN}-\mathrm{T}$ and $\mathrm{MN}-\mathrm{T}+\mathrm{C}$, as well as in retrospective biological dosimetry [47]. The follow-up of populations exposed to low doses of ionizing radiation has demonstrated a higher frequency of $\mathrm{MN}$ with centromere sequences than in controls $[14,46$, 48]. This data can be explained by the higher rate of spontaneous of $\mathrm{MN}-\mathrm{T}+\mathrm{C}$ in the background of $\mathrm{MN}$ in the healthy population, related essentially to a low-dose exposure (chemical or radiation). It may be informative to investigate the number of telomere signals in these MN to determine the role of telomere deletion in these chromosomes. In addition, recent genetic evidence demonstrates that increased rates of whole chromosome missegregation can accelerate oncogenesis $[49,50]$.

These improvements in the detection of MN using the CBMN assay followed by TC staining can explain the accordance of the dose response curve obtained (up to 4 Gy) in this study to the manual dose response curve of the IAEA [2] after uniform staining and that published previously following manual scoring [51] or semi-automated scoring following uniform staining [52].

Nevertheless, we observed evidence of low-dose hypersensitivity (HRS). We demonstrate higher radiation sensitivity per unit dose at $100 \mathrm{mGy}$, which was due not only to the clastogenic effect of irradiation $(\mathrm{MN}-\mathrm{T})$ but also the aneugenic effect $(\mathrm{MN}-\mathrm{T}+\mathrm{C})$, which is 
never considered. These findings show that HRS observed after low-dose exposure may be related to different molecular mechanisms for the generation of radiation-induced cytogenetic effects than those generated at high doses. The scoring of numerical and structural chromosomal aberrations after low-dose exposure could be used to confirm these results [50]. However, Seth et al. [53] observed hypersensitivity after the irradiation of lymphocyte at the G2 phase only and not in G0. This discrepancy may also be due to the range of doses (0.1 to $1.6 \mathrm{~Gy})$ and the protocols used [54].

This improvement of the CBMN assay followed by TC staining permits the detection of not only MN but also MPBs and NBUDs, which are related to chromosomal instability in populations exposed to genotoxic agents or in cancer patients. The interest to improve the detection of TC sequences in NPBs has been driven by the need to know the mechanisms underlying dicentric-chromosome formation. We demonstrate the absence of TC sequences in the bridge after genotoxic exposure, which is usually accompanied by MN-T. However, the presence of TC sequences in the bridge indicates that dicentric-chromosome formation was related to a defect of the telomeres and chromosome end to end fusion [55, 56]. The use of this approach would also make it possible to detect chromosomal instability via the presence of dicentric chromosomes in tumor cells, considered to be an important prognostic factor and a biomarker for complex karyotypes [57-59].

\section{Conclusion:}

The improvement in the detection of $\mathrm{MN}$, their characterization, and reevaluation of the sensitivity of the CBMN assay, as well as the dose-response curves for low and high doses following semi-automated TC staining provides the most precise cytogenetic analysis currently available to determine exposure to genotoxic agents and the monitoring of disease. This work represents a first step towards future studies to reevaluate the background of $\mathrm{MN}$ and NPBs in non-exposed populations and MN in populations exposed to genotoxic agents, as well as the mechanisms of chromosomal instability in cancer patients $[7,9,60]$. The automation of these approaches offers the possibility to achieve high sample throughput for the processing of large cohorts of exposed populations and tumor cells in cancer patients for monitoring, without the need of a high level of expertise level.

\section{Acknowledgements;}


We would like to thank Luis Martins and Luc Morat (CEA Fontenay aux roses) for contributing to cell irradiation. We are indebted to Dr Andreas Plesch (Metasystems) for his technical help.

\section{References:}

[1] OECD 487, Test No. 487: In Vitro Mammalian Cell Micronucleus Test, OECD Publishing.

[2] IAEA, Cytogenetic Dosimetry Applications in Preparedness for and Response to Radiation Emergencies, EPR-Biodose, (2011).

[3] M. Fenech, Cytokinesis-block micronucleus cytome assay, Nature protocols, 2 (2007)1084-1104.

[4] V.S. Dhillon, P. Thomas, G. larmarcovai, M. Kirsch-Volders, S. Bonassi, M. Fenech, Genetic polymorphisms of genes involved in DNA repair and metabolism influence micronucleus frequencies in human peripheral blood lymphocytes, Mutagenesis, 26 (2011) 33-42.

[5] S. Bonassi, R. El-Zein, C. Bolognesi, M. Fenech, Micronuclei frequency in peripheral blood lymphocytes and cancer risk: evidence from human studies, Mutagenesis, 26 (2011) 93-100.

[6] C. Bolognesi, S. Bonassi, S. Knasmueller, M. Fenech, M. Bruzzone, C. Lando, M. Ceppi, Clinical application of micronucleus test in exfoliated buccal cells: A systematic review and metanalysis, Mutation research. Reviews in mutation research, 766 (2015) 20-31.

[7] A. Podrimaj-Bytyqi, A. Borovecki, Q. Selimi, S. Manxhuka-Kerliu, G. Gashi, I.R. Elezaj, The frequencies of micronuclei, nucleoplasmic bridges and nuclear buds as biomarkers of genomic instability in patients with urothelial cell carcinoma, Scientific reports, 8 (2018) 17873.

[8] M. Palmitelli, C. Stanganelli, F. Stella, A. Krzywinski, R. Bezares, M. Gonzalez Cid, I. Slavutsky, Analysis of basal chromosome instability in patients with chronic lymphocytic leukaemia, Mutagenesis, 34 (2019) 245-252.

[9] A.K. Baergen, L.M. Jeusset, Z. Lichtensztejn, K.J. McManus, Diminished Condensin Gene Expression Drives Chromosome Instability That May Contribute to Colorectal Cancer Pathogenesis, 11 (2019).

[10] Z. Siama, M. Zosang-Zuali, A. Vanlalruati, G.C. Jagetia, K.S. Pau, N.S. Kumar, Chronic low dose exposure of hospital workers to ionizing radiation leads to increased micronuclei frequency and reduced antioxidants in their peripheral blood lymphocytes, International journal of radiation biology, 95 (2019) 697-709.

[11] G. Gajski, D. Milkovic, M. Ranogajec-Komor, S. Miljanic, V. Garaj-Vrhovac, Application of dosimetry systems and cytogenetic status of the child population exposed to diagnostic X-rays by use of the cytokinesis-block micronucleus cytome assay, Journal of applied toxicology : JAT, 31 (2011) 608-617.

[12] K. Kanagaraj, S. Abdul Syed Basheerudeen, G. Tamizh Selvan, M.T. Jose, A. Ozhimuthu, S. Panneer Selvam, S. Pattan, V. Perumal, Assessment of dose and DNA damages in individuals exposed to low dose and low dose rate ionizing radiations during computed tomography imaging, Mutation research. Genetic toxicology and environmental mutagenesis, 789-790 (2015) 1-6.

[13] G.K. Livingston, I.K. Khvostunov, Cytogenetic effects of radioiodine therapy: a 20-year follow-up study, 55 (2016) 203-213.

[14] A. Vral, V. Decorte, J. Depuydt, A. Wambersie, H. Thierens, A semiautomated FISHbased micronucleuscentromere assay for biomonitoring of hospital workers exposed to low doses of ionizing radiation, Molecular medicine reports, 14 (2016) 103-110. 
[15] M. Fenech, S. Bonassi, The effect of age, gender, diet and lifestyle on DNA damage measured using micronucleus frequency in human peripheral blood lymphocytes, Mutagenesis, 26 (2011) 4349.

[16] G.K. Livingston, M. Escalona, A. Foster, A.S. Balajee, Persistent in vivo cytogenetic effects of radioiodine therapy: a 21-year follow-up study using multicolor FISH, Journal of radiation research, 59 (2018) 10-17.

[17] A. Kus, J. Kwasniewska, R. Hasterok, Brachypodium distachyon - A Useful Model in the Qualification of Mutagen-Induced Micronuclei Using Multicolor FISH, PloS one, 12 (2017) e0170618.

[18] A. Rossnerova, K. Honkova, J. Pavlikova, Z.F. Skalicka, R. Havrankova, I. Solansky, P. Rossner, Jr., R.J. Sram, F. Zolzer, Mapping the factors affecting the frequency and types of micronuclei in an elderly population from Southern Bohemia, Mutation research, 793-794 (2016) 32-40.

[19] J. Depuydt, A. Baeyens, S. Barnard, C. Beinke, A. Benedek, P. Beukes, I. Buraczewska, F. Darroudi, S. De Sanctis, I. Dominguez, O. Monteiro Gil, V. Hadjidekova, E. Kis, U. Kulka, F. Lista, K. Lumniczky, R. M'Kacher, J. Moquet, D. Obreja, U. Oestreicher, J. Pajic, N. Pastor, L. Popova, E. Regalbuto, M. Ricoul, L. Sabatier, J. Slabbert, S. Sommer, A. Testa, H. Thierens, A. Wojcik, A. Vral, RENEB intercomparison exercises analyzing micronuclei (Cytokinesis-block Micronucleus Assay), International journal of radiation biology, 93 (2017) 36-47.

[20] R. M'kacher, E.E.L. Maalouf, M. Ricoul, L. Heidingsfelder, E. Laplagne, C. Cuceu, W.M. Hempel, B. Colicchio, A. Dieterlen, L. Sabatier, New tool for biological dosimetry: Reevaluation and automation of the gold standard method following telomere and centromere staining, Mutation Research/Fundamental and Molecular Mechanisms of Mutagenesis, 770 (2014) 45-53.

[21] R. M'Kacher, E.E. Maalouf, M. Ricoul, L. Heidingsfelder, E. Laplagne, C. Cuceu, W.M. Hempel, B. Colicchio, A. Dieterlen, L. Sabatier, New tool for biological dosimetry: reevaluation and automation of the gold standard method following telomere and centromere staining, Mutation research, 770 (2014) 45-53.

[22] R. M'Kacher, E. El Maalouf, G. Terzoudi, M. Ricoul, L. Heidingsfelder, I. Karachristou, E. Laplagne, W.M. Hempel, B. Colicchio, A. Dieterlen, G. Pantelias, L. Sabatier, Detection and automated scoring of dicentric chromosomes in nonstimulated lymphocyte prematurely condensed chromosomes after telomere and centromere staining, International journal of radiation oncology, biology, physics, 91 (2015) 640-649.

[23] A. Kaddour, B. Colicchio, D. Buron, E. El Maalouf, E. Laplagne, C. Borie, M. Ricoul, A. Lenain, W.M. Hempel, L. Morat, M. Al Jawhari, C. Cuceu, L. Heidingsfelder, E. Jeandidier, G. Deschênes, A. Dieterlen, M. El May, T. Girinsky, A. Bennaceur-Griscelli, P. Carde, L. Sabatier, R. M’kacher, Transmission of Induced Chromosomal Aberrations through Successive Mitotic Divisions in Human Lymphocytes after In Vitro and In Vivo Radiation, Scientific reports, 7 (2017).

[24] K. Vande Loock, E. Fthenou, I. Decordier, G. Chalkiadaki, M. Keramarou, G. Plas, M. Roelants, J. Kleinjans, L. Chatzi, F. Merlo, M. Kogevinas, M. Kirsch-Volders, Maternal and gestational factors and micronucleus frequencies in umbilical blood: the NewGeneris Rhea cohort in Crete, Environmental health perspectives, 119 (2011) 1460-1465.

[25] I. Decordier, A. Papine, G. Plas, S. Roesems, K. Vande Loock, J. Moreno-Palomo, E. Cemeli, D. Anderson, A. Fucic, R. Marcos, F. Soussaline, M. Kirsch-Volders, Automated image analysis of cytokinesis-blocked micronuclei: an adapted protocol and a validated scoring procedure for biomonitoring, Mutagenesis, 24 (2009) 85-93.

[26] F. Finot, A. Kaddour, L. Morat, I. Mouche, N. Zaguia, C. Cuceu, D. Souverville, S. Negrault, O. Cariou, A. Essahli, N. Prigent, J. Saul, F. Paillard, L. Heidingsfelder, P. Lafouge, M. Al Jawhari, W.M. Hempel, M. El May, B. Colicchio, A. Dieterlen, E. Jeandidier, L. Sabatier, J. Clements, R. M'Kacher, Genotoxic risk of ethyl-paraben could be related to telomere shortening, Journal of applied toxicology : JAT, 37 (2017) 758-771.

[27] V. Diehl, M. Pfreundschuh, C. Fonatsch, H. Stein, M. Falk, H. Burrichter, M. Schaadt, Phenotypic and genotypic analysis of Hodgkin's disease derived cell lines: histopathological and clinical implications, Cancer surveys, 4 (1985) 399-419. 
[28] R. Ber, G. Klein, M. Moar, S. Povey, A. Rosen, A. Westman, E. Yefenof, J. Zeuthen, Somatic cell hybrids between human lymphoma lines. IV. Establishment and characterization of a P3HR-1/Daudi hybrid, International journal of cancer. Journal international du cancer, 21 (1978) 707-719.

[29] R. M'kacher, C. Cuceu, M. Al Jawhari, L. Morat, M. Frenzel, G. Shim, A. Lenain, W.M. Hempel, S. Junker, T. Girinsky, B. Colicchio, A. Dieterlen, L. Heidingsfelder, C. Borie, N. Oudrhiri, A. BennaceurGriscelli, O. Moralès, S. Renaud, Z. Van de Wyngaert, E. Jeandidier, N. Delhem, P. Carde, The Transition between Telomerase and ALT Mechanisms in Hodgkin Lymphoma and Its Predictive Value in Clinical Outcomes, Cancers, 10 (2018) 169.

[30] O. Cariou, N. Laroche-Prigent, S. Ledieu, I. Guizon, F. Paillard, V. Thybaud, Cytosine arabinoside, vinblastine, 5-fluorouracil and 2-aminoanthracene testing in the in vitro micronucleus assay with L5178Y mouse lymphoma cells at Sanofi Aventis, with different cytotoxicity measurements, in support of the draft OECD Test Guideline on In Vitro Mammalian Cell Micronucleus Test, Mutation research, 702 (2010) 148-156.

[31] C. Schunck, T. Johannes, D. Varga, T. Lorch, A. Plesch, New developments in automated cytogenetic imaging: unattended scoring of dicentric chromosomes, micronuclei, single cell gel electrophoresis, and fluorescence signals, Cytogenetic and genome research, 104 (2004) 383-389. [32] O.B. Vrndic, O.M. Milosevic-Djordjevic, L.C. Mijatovic Teodorovic, M.Z. Jeremic, I.M. Stosic, D.V. Grujicic, S.T. Zivancevic Simonovic, Correlation between micronuclei frequency in peripheral blood lymphocytes and retention of 131-I in thyroid cancer patients, The Tohoku journal of experimental medicine, 229 (2013) 115-124.

[33] G. Iarmarcovai, M. Ceppi, A. Botta, T. Orsiere, S. Bonassi, Micronuclei frequency in peripheral blood lymphocytes of cancer patients: a meta-analysis, Mutation research,659 (2008) 274-283.

[34] G. Speit, Does the recommended lymphocyte cytokinesis-block micronucleus assay for human biomonitoring actually detect DNA damage induced by occupational and environmental exposure to genotoxic chemicals?, Mutagenesis, 28 (2013) 375-380.

[35] M. Fenech, N. Holland, E. Zeiger, W.P. Chang, S. Burgaz, P. Thomas, C. Bolognesi, S. Knasmueller, M. Kirsch-Volders, S. Bonassi, The HUMN and HUMNxL international collaboration projects on human micronucleus assays in lymphocytes and buccal cells--past, present and future, Mutagenesis, 26 (2011) 239-245.

[36] H.K. Lindberg, G.C. Falck, H. Jarventaus, H. Norppa, Characterization of chromosomes and chromosomal fragments in human lymphocyte micronuclei by telomeric and centromeric FISH, Mutagenesis, 23 (2008) 371-376.

[37] A. Wojda, M. Witt, Manifestations of ageing at the cytogenetic level, Journal of applied genetics, 44 (2003) 383-399.

[38] A. Wojda, E. Zietkiewicz, M. Witt, Effects of age and gender on micronucleus and chromosome nondisjunction frequencies in centenarians and younger subjects, Mutagenesis, 22 (2007) 195-200.

[39] J. Catalan, K. Autio, E. Kuosma, H. Norppa, Age-dependent inclusion of sex chromosomes in lymphocyte micronuclei of man, American journal of human genetics, 63 (1998)1464-1472.

[40] H. Norppa, G.C. Falck, What do human micronuclei contain?, Mutagenesis, 18 (2003) 221-233.

[41] A. Baeyens, R. Swanson, O. Herd, E. Ainsbury, T. Mabhengu, P. Willem, H. Thierens, J.P. Slabbert, A. Vral, A semi-automated micronucleus-centromere assay to assess low-dose radiation exposure in human lymphocytes, International journal of radiation biology, 87 (2011) 923-931.

[42] B.D. Spycher, J.E. Lupatsch, M. Zwahlen, M. Roosli, F. Niggli, M.A. Grotzer, J. Rischewski, M. Egger, C.E. Kuehni, Background ionizing radiation and the risk of childhood cancer: a census-based nationwide cohort study, Environmental health perspectives, 123 (2015) 622-628.

[43] M.S. Pearce, J.A. Salotti, M.P. Little, K. McHugh, C. Lee, K.P. Kim, N.L. Howe, C.M. Ronckers, P. Rajaraman, A.W. Sir Craft, L. Parker, A. Berrington de Gonzalez, Radiation exposure from CT scans in childhood and subsequent risk of leukaemia and brain tumours: a retrospective cohort study, Lancet (London, England), 380 (2012) 499-505.

[44] J.J. Boei, A.T. Natarajan, Detection of chromosome malsegregation to the daughter nuclei in cytokinesis-blocked transgenic mouse splenocytes, Chromosome research : an international journal on the molecular, supramolecular and evolutionary aspects of chromosome biology, 3 (1995) 45-53. 
[45] M.P. Hande, J.J. Boei, A.T. Natarajan, Induction and persistence of cytogenetic damage in mouse splenocytes following whole-body X-irradiation analysed by fluorescence in situ hybridization. II. Micronuclei, International journal of radiation biology, 70 (1996) 375-383.

[46] H. Thierens, A. Vral, R. Morthier, B. Aousalah, L. De Ridder, Cytogenetic monitoring of hospital workers occupationally exposed to ionizing radiation using the micronucleus centromere assay, Mutagenesis, 15 (2000) 245-249.

[47] U. Kulka, L. Ainsbury, M. Atkinson, S. Barnard, R. Smith, J.F. Barquinero, L. Barrios, C. Bassinet, C. Beinke, A. Cucu, F. Darroudi, P. Fattibene, E. Bortolin, S.D. Monaca, O. Gil, E. Gregoire, V.

Hadjidekova, S. Haghdoost, V. Hatzi, W. Hempel, R. Herranz, A. Jaworska, C. Lindholm, K. Lumniczky, R. M'Kacher, S. Mortl, A. Montoro, J. Moquet, M. Moreno, M. Noditi, A. Ogbazghi, U. Oestreicher, F. Palitti, G. Pantelias, I. Popescu, M.J. Prieto, S. Roch-Lefevre, U. Roessler, H. Romm, K. Rothkamm, L. Sabatier, N. Sebastia, S. Sommer, G. Terzoudi, A. Testa, H. Thierens, F. Trompier, I. Turai, C. Vandevoorde, P. Vaz, P. Voisin, A. Vral, F. Ugletveit, A. Wieser, C. Woda, A. Wojcik, Realising the European network of biodosimetry: RENEB-status quo, Radiation protection dosimetry, 164 (2015) 42-45.

[48] S. Bouraoui, S. Mougou, A. Drira, F. Tabka, N. Bouali, N. Mrizek, H. Elghezal, A. Saad, A cytogenetic approach to the effects of low levels of ionizing radiation (IR) on the exposed Tunisian hospital workers, International journal of occupational medicine and environmental health, 26 (2013) 144-154.

[49] K. Crasta, N.J. Ganem, R. Dagher, A.B. Lantermann, E.V. Ivanova, Y. Pan, L. Nezi, A. Protopopov, D. Chowdhury, D. Pellman, DNA breaks and chromosome pulverization from errors in mitosis, Nature, 482 (2012) 53-58.

[50] G. Farkas, Z. Juranyi, G. Szekely, Z.S. Kocsis, S. Gundy, Relationship between spontaneous frequency of aneuploidy and cancer risk in 2145 healthy Hungarian subjects, Mutagenesis, 31 (2016) 583-588.

[51] P. Voisin, M. Benderitter, V. Chambrette, M. Claraz, M. Delbos, V. Durand, N. Paillole, L. Roy, I. Sorokine-Durm, La dosimétrie cytogénétique de l'accident d'irradiation, Radioprotection, 37 (2002) 27-40.

[52] J. Depuydt, A. Baeyens, S. Barnard, C. Beinke, A. Benedek, P. Beukes, I. Buraczewska, F.Darroudi, S. De Sanctis, I. Dominguez, O. Monteiro Gil, V. Hadjidekova, E. Kis, U. Kulka, F. Lista, K. Lumniczky, R. M'Kacher, J. Moquet, D. Obreja, U. Oestreicher, J. Pajic, N. Pastor, L. Popova, E. Regalbuto, M. Ricoul, L. Sabatier, J. Slabbert, S. Sommer, A. Testa, H. Thierens, A. Wojcik, A. Vral, RENEB intercomparison exercises analyzing micronuclei (Cytokinesis-block Micronucleus Assay), International journal of radiation biology, (2016) 1-12.

[53] I. Seth, M.C. Joiner, J.D. Tucker, Cytogenetic low-dose hyperradiosensitivity is observed in human peripheral blood lymphocytes, International journal of radiation oncology, biology, physics, 91 (2015) 82-90.

[54] R. M'Kacher, In Regard to Seth et al, International journal of radiation oncology, biology, physics, 92 (2015) 701-702.

[55] C. Cuceu, B. Colicchio, E. Jeandidier, S. Junker, G. Shim, L.F. Plassa, J. Mika, M. Frenzel, M. Al Jawhari, W.M. Hempel, G. O'Brien, A. Lenain, L. Morat, T. Girinsky, A. dieterlen, J. Polanska, C. Badie, P. Carde, R. M'Kacher, Independent mechanisms lead to genomic instability in Hodgkin lymphoma: Microsatellite or chromosomal instability related to telomere end fusion or DNA repair defects, submitted on cancers, (2018).

[56] C. Cuceu, W.M. Hempel, L. Sabatier, J. Bosq, P. Carde, R. M'Kacher, Chromosomal Instability in Hodgkin Lymphoma: An In-Depth Review and Perspectives, Cancers, 10(2018).

[57] D. Gisselsson, L. Pettersson, M. Hoglund, M. Heidenblad, L. Gorunova, J. Wiegant, F. Mertens, P. Dal Cin, F. Mitelman, N. Mandahl, Chromosomal breakage-fusion-bridge events cause genetic intratumor heterogeneity, Proceedings of the National Academy of Sciences of the United States of America, 97 (2000) 5357-5362. 
[58] R.N. Mackinnon, L.J. Campbell, The role of dicentric chromosome formation and secondary centromere deletion in the evolution of myeloid malignancy, Genetics research international, 2011 (2011) 643628.

[59] K. Yamamoto, H. Matsuoka, Y. Funakoshi, K. Yakushijin, A. Okamura, T. Itoh, H. Minami, A novel dicentric chromosome, dic(9;9)(p12;q34), leading to trisomy 9 in follicular lymphoma without $\mathrm{t}(14 ; 18)$, Leukemia research, 35 (2011) e100-103.

[60] C.Z. Zhang, A. Spektor, H. Cornils, J.M. Francis, E.K. Jackson, S. Liu, M. Meyerson, D. Pellman, Chromothripsis from DNA damage in micronuclei, Nature, 522 (2015) 179-184. 


\section{Legend:}

Figure 1: Detection of MN after TC staining. (A) Uniform staining demonstrating the difficulty to detect MN due to the weak intensity of DAPI staining of MN relative to the nucleus. (B) Staining of telomere and centromere sequences showing better visualization of MN. TC staining permits easy identification of the cytoskeleton (C), MN with only telomere sequences (D), MN without any telomere or centromere sequences (E), and MN with telomere and centromere sequences $(\mathrm{F})$.

Figure 2: Detection of clastogenic and aneugenic effects in lymphocytes treated with mitomycin C or vinblastine. (A) Significant increase in the frequency of $M N$ with only telomere sequences after exposure to various doses of mitomycin $\mathrm{C}$ (clastogenic effect). (B) Significant increase in the frequency of MN with telomere and centromere sequences after vinblastine exposure (aneugenic effect).

Figure 3: Dose response curves obtained after the scoring of total MN, MN-T and MN-T+C. and the frequency of MN without any signal following TC staining was added to the frequency of MN-T. (A) Dose-response curve obtained for up to $4 \mathrm{~Gy}$ at a dose rate of 0.61 Gy/min. (B) Zoom of below 1 Gy of the dose response curve, demonstrating the contrasting effects of low- and high-dose radiation exposure. A high frequency of $\mathrm{MN} \mathrm{T}+\mathrm{C}$ was observed leading to an aneugenic effect of low-dose exposure. The frequency of $\mathrm{MN}-\mathrm{T}+\mathrm{C}$ increased up to $0.5 \mathrm{~Gy}$ and decreased thereafter.

Figure 4: (A) Ratio between $\mathrm{MN}-\mathrm{T}+\mathrm{C}$ and $\mathrm{MN}-\mathrm{T}$, showing a linear relation after low-dose exposure ( 0 to $0.5 \mathrm{~Gy}$ ). (B) Radiation sensitivity of cells after scoring for the total frequency of $\mathrm{MN}$, the frequency of MN-T, and MN-T+C per dose. Hyper-radiosensitivity was observed after 0.1 Gy of exposure.

Figure 5: Elucidation of DNA repair mechanisms following TC staining. (A) The presence of a bridge without TC sequences after exposure to a genotoxic agent associated with the presence of MN-T leading to the presence of induced dicentric chromosome (B) The presence of TC sequences in the bridge of the HDLM2 Hodgkin lymphoma cell line, demonstrating the presence of a dicentric chromosome associated with telomere dysfunction. (C-D) Characterization of NBUDs following TC staining demonstrating the presence of an NBUD with telomere and centromere sequences as well as an NBUD without any signal. 
Figure1: Detection of MN after TC staining. Arrows indicate MN. (A) Uniform staining demonstrates the difficult detection of $\mathrm{MN}$ due to the weak intensity of DAPI-stained $\mathrm{MN}$ relative to the nucleus. (B) Staining of telomere and centromere sequences allows improved visualization of MN. (C) TC staining permits easy identification of the cytoplasm, (D) the detection of $\mathrm{MN}$ with only telomere sequences, (E) $\mathrm{MN}$ without any telomere or centromere sequences, (F) MN with telomere and centromere sequences.
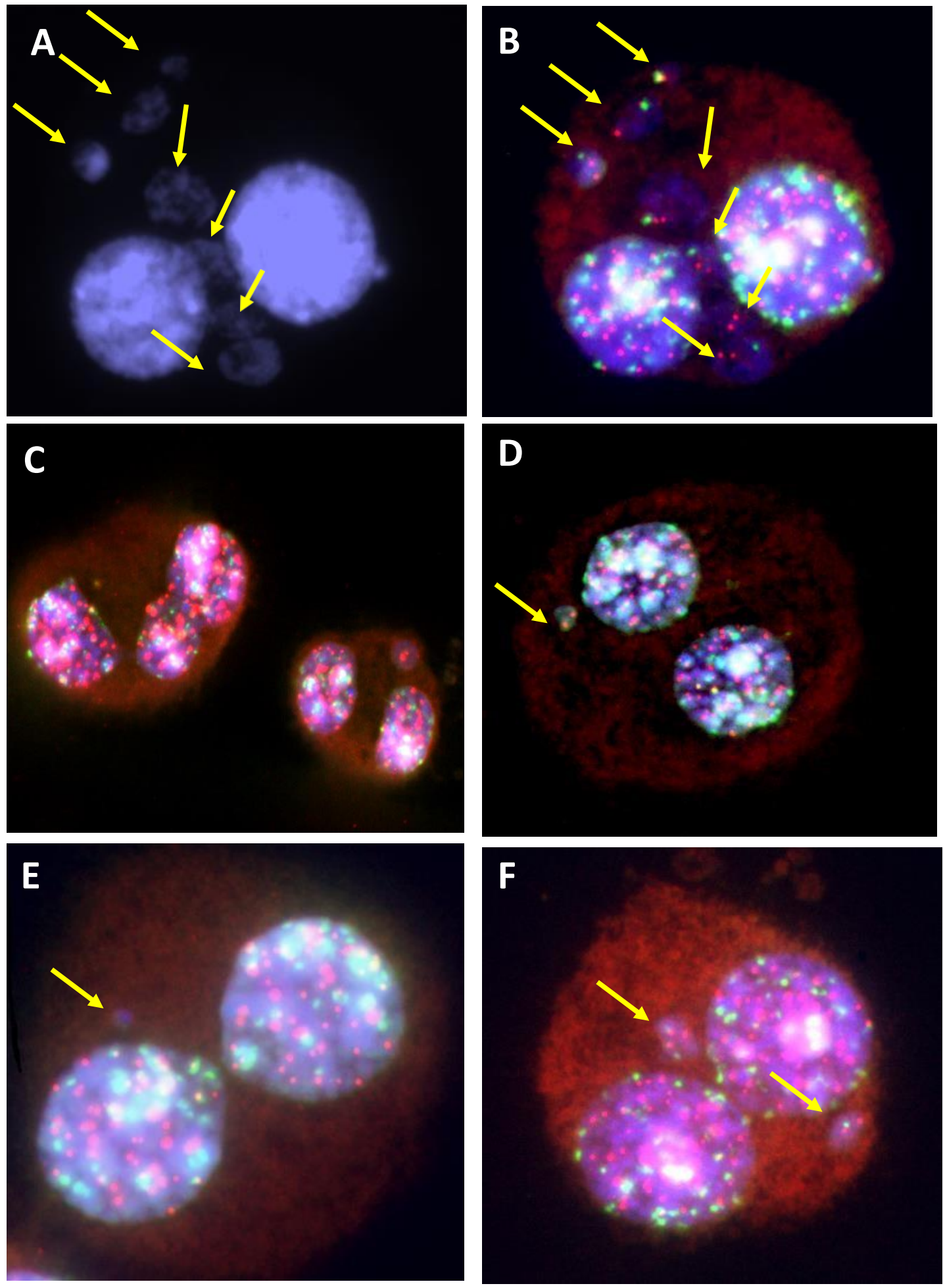


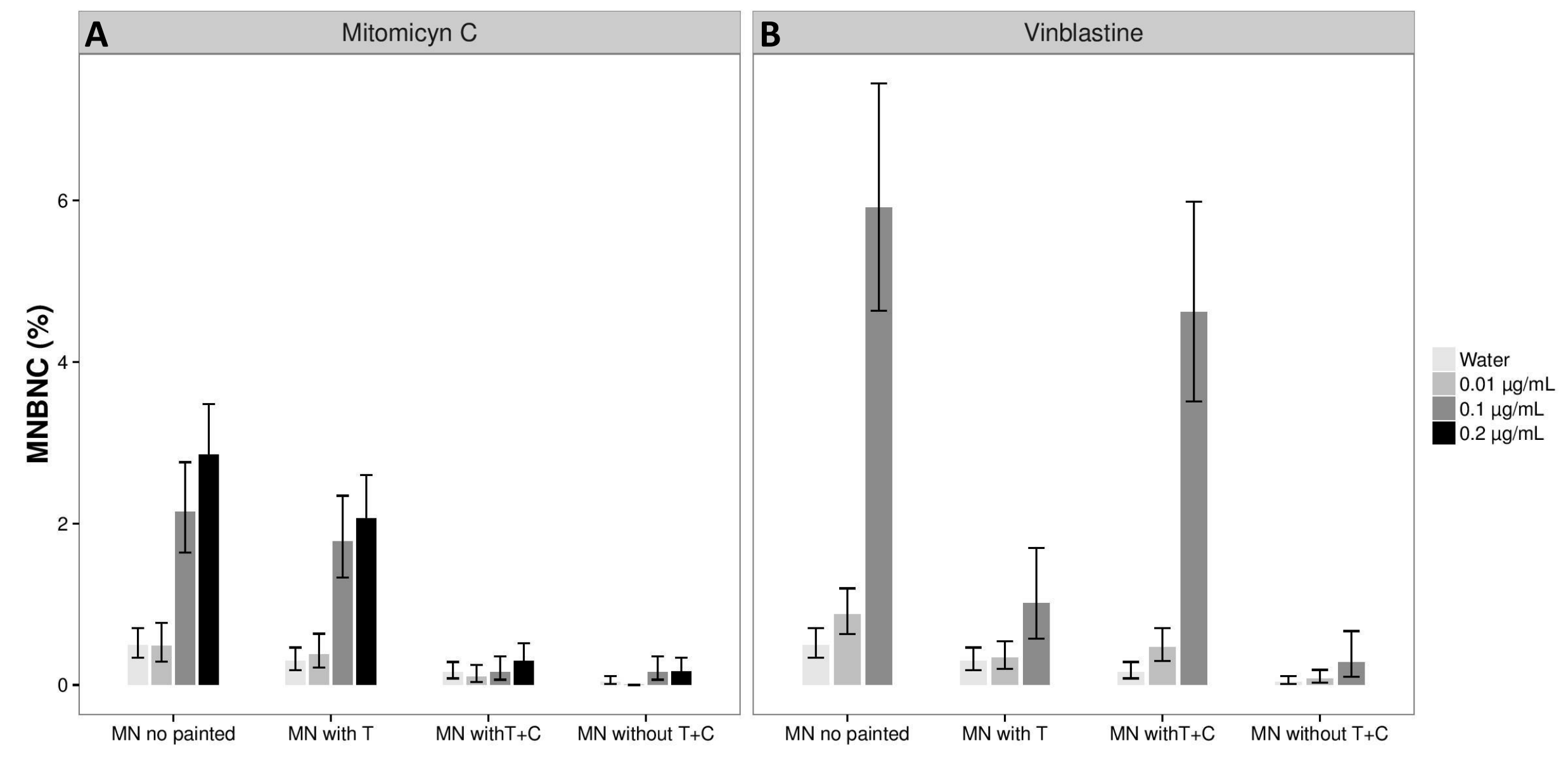




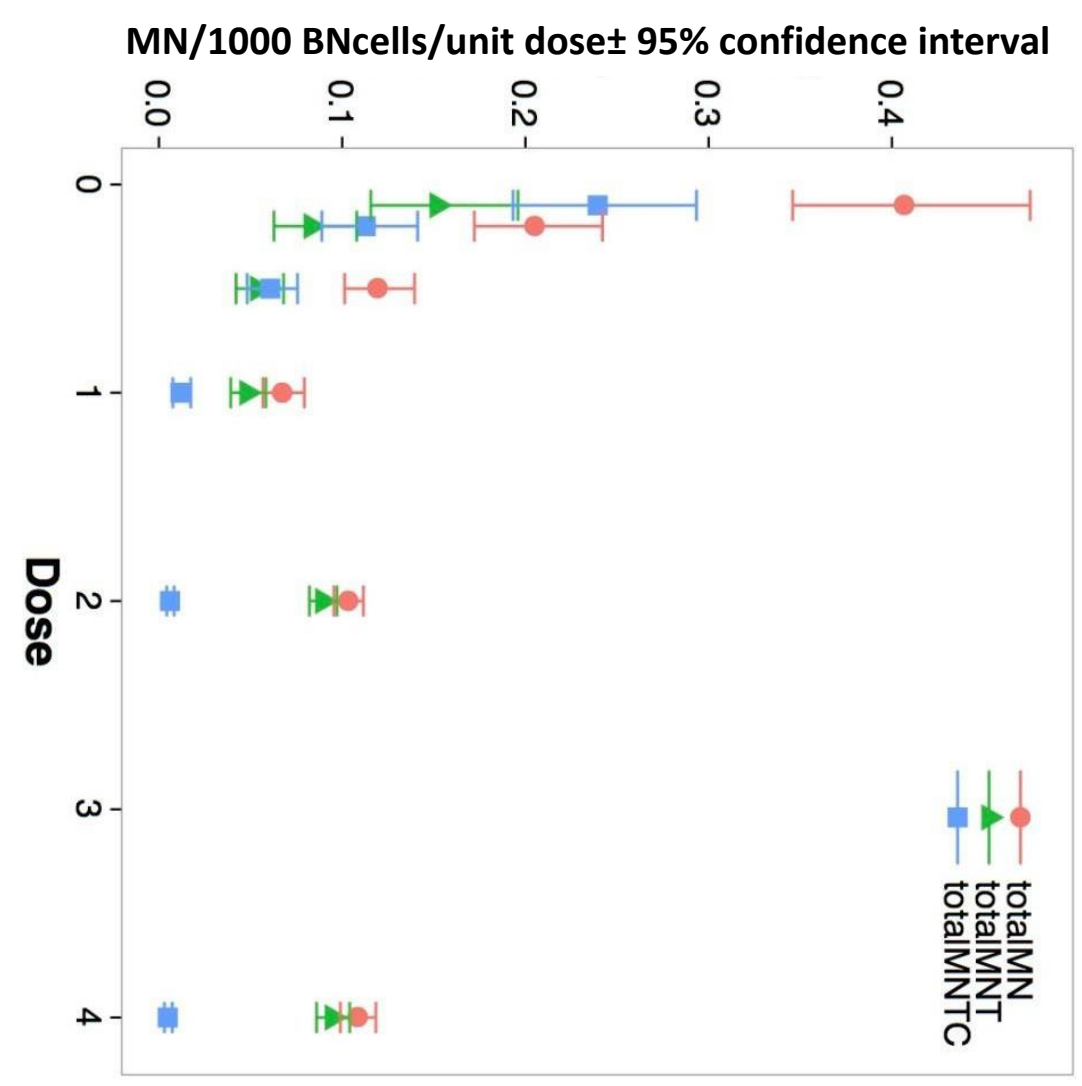



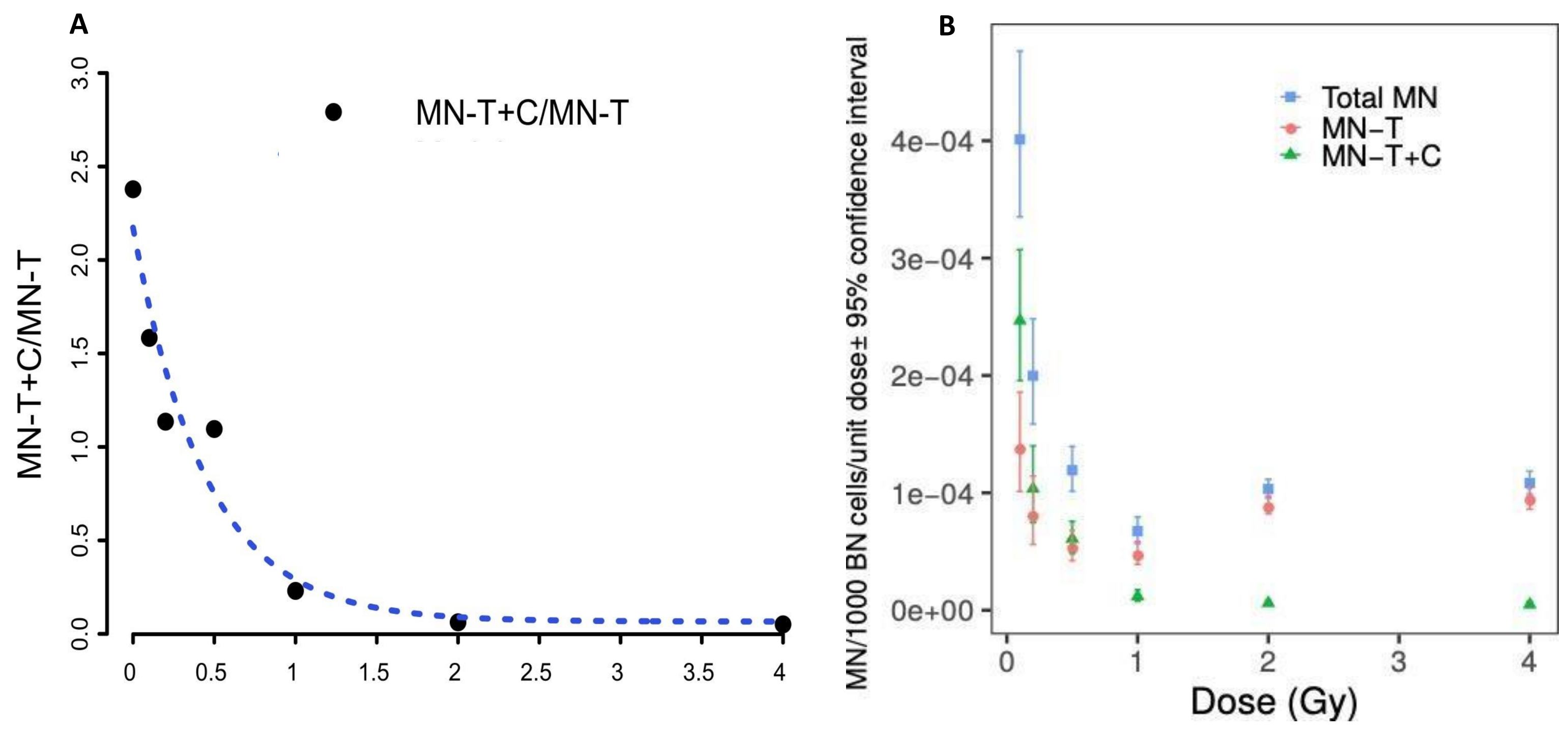

Dose (Gy) 
